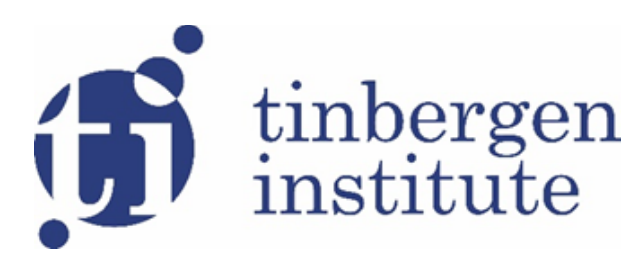

TI 2020-016/II

Tinbergen Institute Discussion Paper

\title{
Peaceful Agreements to Share a River
}

Rene van den Brink ${ }^{1}$

Saish Nevrekar ${ }^{2}$

${ }^{1}$ Vrije Universiteit Amsterdam

2 Universidad Carlos III de Madrid, Spain 
Tinbergen Institute is the graduate school and research institute in economics of Erasmus University Rotterdam, the University of Amsterdam and Vrije Universiteit Amsterdam.

Contact: discussionpapers@tinbergen.nl

More TI discussion papers can be downloaded at https://www.tinbergen.nl

Tinbergen Institute has two locations:

Tinbergen Institute Amsterdam

Gustav Mahlerplein 117

1082 MS Amsterdam

The Netherlands

Tel.: +31(0)205984580

Tinbergen Institute Rotterdam

Burg. Oudlaan 50

3062 PA Rotterdam

The Netherlands

Tel.: +31(0)10408 8900 


\title{
Peaceful Agreements to Share a River
}

\author{
Rene van den Brink* \\ Saish Nevrekar ${ }^{\dagger}$
}

March, 2020

\begin{abstract}
This paper develops a model of conflict resolution over scarce water in a trans-boundary river. In our model, we consider countries that are located along a river and made a military investment. Given these investments and their location along the river, they sequentially bargain over the surplus of water, or decide to engage in a military conflict with their upstream neighbour. The probability of winning a military conflict is determined by a contest success function which depends on the military investments made before. We speak about a peaceful agreement if the countries rationally decide to bargain over the water instead of engaging into a military conflict. We show that, if all benefit functions are nonnegative, increasing and concave, then for every level of military investment, there always exists a peaceful agreement where every country prefers to bargain peacefully for the water. We provide a scenario that yields one such a peaceful agreement.
\end{abstract}

Keywords: River sharing, peaceful agreement, contest success function, subgame perfect equilibrium

JEL Classification: C78, D62, D74, Q25

*Vrije Universiteit Amsterdam, E-mail: j.r.vanden.brink@vu.nl.

†Universidad Carlos III de Madrid, E-mail: snevreka@eco.uc3m.es. 


\section{Introduction}

In this paper, we develop a model of conflict resolution over scarce water in a trans-boundary river. Using contest success functions, we develop a decision model where, after investing effort into building some military, the countries either bargain over the (surplus of) river water or engage in warfare.

The problem of river water sharing is of considerable practical importance: 148 rivers in the world flow through two countries, 30 through three, 9 through four, and 13 through five or more (Barret (1994)). International law states that the nations along a transboundary river should mutually agree on sharing the river through negotiations, but it is not specified to what extend unilateral decisions can be made in the absence of agreement. Moreover, such negotiations are often deadlocked, because almost all governments in water stressed regions became aware of the water issues after having experienced serious shortages. Unless politics either deepens or broadens the water agenda, as in e.g. Bennett, Ragland and Yolles (1998), the situation is most likely to stay put or might even deteriorate ending in conflict. Many researchers in economics and game theory have addressed the water issue, see for instance Carraro, Machiori and Sgobbi (2005a,b), Dinar, Ratner and Yaron (1992) and Dinar, Kemper, Blomquist, Diez and Sine (2005) for extensive surveys.

Various approaches are followed to study international river water allocation. Ambec and Sprumont (2002) were the first to apply cooperative games to this problem and provided cooperative solutions to river water sharing. Supalla, Klaus, Yeboah and Bruins (2002) consider auction mechanisms, while Ansink and Weikard (2012) provide sequential solutions to the river sharing problem using a bankruptcy rule. Kilgour and Dinar $(1995,2001)$ consider efficient and stable water sharing agreements under variable flow rates, while Ambec, Dinar and Mckinney (2013) look at the effect of reduced flows on the credible agreements. An overview of the cooperative approach to river water allocation can be found in Béal, Ghintran, Rémila and Solal $(2013)^{1}$.

\footnotetext{
${ }^{1} \mathrm{~A}$ different but related problem is that of allocating responsibility for polluting a river as considered in, e.g. Ni and Wang (2007), Dong, Ni and Wang (2012), Alcalde-Unzu, Gómez-Rua and Molis (2015), Ambec and Ehlers (2016) and van den Brink, He and Huang (2018).
} 
Since there is no binding international law governing the allocation of water in international rivers, International Water Law defines several principles to prevent or resolve disputes on water allocation within an international water basin, see also Kilgour and Dinar (1995). According to the 1966 Helsinki Document two considerations that are to be included when distributing the welfare from allocating the water are 'efficiency of the water use' and 'Pareto optimality'. This implies that an agreement should involve all countries along the river. But since these principles are not binding, we should take into account that countries who do not join the agreement might threaten with warfare. In this paper, we show that also in these cases, a peaceful agreement is possible.

We consider situations where countries interact with their direct (upstream and downstream) neighbours on the river. Each pair of neighbours (link) can negotiate about sharing the river water, or engage in warfare. So, the outcome of bilateral bargaining is either an agreed water sharing or war. In case of war, the outcome (forced water sharing) is determined by a contest success function where the winning probabilities depend on the military investments done before. This military 'threat' sets the range for water sharing agreements in the negotiations over water. Given military investments, an equilibrium is a water sharing (obtained either through a negotiated agreement or warfare). An equilibrium where the water sharing is obtained through a negotiated agreement is called a peaceful agreement. This implies that it satisfies a no conflict condition which requires that, for each pair of neighbouring countries, and for every given military investments, the payoffs from bargaining are at least equal to the payoffs from warfare.

Our main result shows that for every profile of military investments, if benefit functions are nonnegative, increasing and concave, then there always exists a range of water sharings that can be obtained by a peaceful agreement. So, whatever are the military investments, a peaceful agreement is always possible. This is an important result since it implies that, although the military capacities of countries might be a threat and make it more difficult to get to an agreement and avoid warfare, it is always possible to have a peaceful agreement. This result is also of great societal importance since scarcity of (clean and usable) river water is a growing problem and one of the reasons for warfare. This will only become a bigger threat in the future when clean water becomes more scarce, especially when earlier investments made in military power increase the probability of a war.

Notice that, although we describe a two stage decision problem where in the first stage the 
countries choose their military investment, and in the second stage they decide on bargaining or warfare, we only focus on the rational decisions in the second stage, taking the military investments in stage 1 as given. This is because countries invest in military to protect themselves against possible future aggressors, or to initiate war themselves. Often these decisions are not based on optimizing behavior, but simply from a need to protect oneself. Alternative theories, for example deterence theory, can explain such military investments.

Besides showing the existence of a peaceful agreement, we provide an extensive form game that has a unique Subgame Pefect Equlibrium (SPE) that implements a possible peaceful agreement. In this mechanism, neighbouring countries bargain bilateral over water. Bargaining between countries occurs sequentially, starting with the two most downstream countries and, after they resolve their bargaining (either ending in an agreement or ending in warfare), the next two countries upstream the river resolve their bargaining. This continues until the bargaining between the two most upstream countries is resolved. In this bargaining, the country who is the proposer has the upper hand. Therefore, the proposer can be determined by applying certain water allocation principles from International Water Law. In this paper, we apply the well-established principle of Absolute Territorial Sovereignty (ATS), or Harmon doctrine, which requires that an agent has absolute sovereignty over the area of any river basin on its territory, and thus it allows agents to use any water that flows into the river on their territory without taking into account what consequences this might have for their downstream countries. This gives the upstream countries the upper hand, and in each bilateral bargaining between two neighoring countries, it will be the upstream country who proposes a sharing of the water that is available. The downstream country responds to this proposal. On its turn, the downstream country is the proposer in the bargaining with its downstream neighbour, while the upstream country is responder in the bargaining with its upstream neighbour.

The paper is organized as follows. Section 2 describes the model, while Section 3 contains the definition of a peaceful agreement and the main existence result. In Section 4, we describe a scenario that yields a specific peaceful agreement, where motivated by the ATS principle, the 'bargaining advantage' is assigned to the upstream countries. Section 5 contains concluding remarks. Finally, there are two appendices, one with the proof of the main results, and one with a full description of the mechanism of Section 4. 


\section{The model}

Let $\pi=(1,2 \ldots, n)$ be an ordering representing a linear river structure over a set of countries $N=\{1, \ldots, n\}$. The river originates at country 1 , sequentially flows through countries $2, \ldots, n-1$, to end at country $n$ from where it flows into an ocean, sea or lake. The river flow increases by $e_{k}$ at each country $k=1, \ldots, n$, with $e_{1}$ the amount of water from the source at country 1 . We assume that $e_{k}$ is the surplus flow after the country's survival needs have been met.

The nonnegative amount of water available for consumption to country $k$ is $X_{k}$. Country $k$ consumes an amount $\delta_{k} X_{k}, \delta_{k} \in[0,1]$, of this water inflow, and allows $\left(1-\delta_{k}\right) X_{k}$ to flow to the next (downstream) country. The available water $X_{k}$ can be recursively written as

$$
X_{k}=\left(1-\delta_{k-1}\right) X_{k-1}+e_{k}, k=1, \ldots n \text {, where } X_{0}=0 \text { and } \delta_{0}=0 .
$$

For completeness, we take $\delta_{n}=1$, so the most downstream country can keep all available water

for itself. Note that $X_{k}$ is at most equal to $\sum_{i=1}^{k} e_{i}$, a maximum which is reached when all upstream countries do not consume any water: $\delta_{1}=\ldots=\delta_{k-1}=0$. The benefit that country $k=1, \ldots, n$ derives from water consumption is given by a benefit function $B_{k}: \mathbb{R}_{+} \rightarrow \mathbb{R}_{+}$, where $B_{k}\left(X_{k}\right)$ is the benefit of consuming the nonnegative amount $X_{k}$ of water by country $k$. We assume that the function $B_{k}: \mathbb{R}_{+} \rightarrow \mathbb{R}_{+}$is nonnegative, increasing and concave. ${ }^{2}$

We assume that the countries have made some prior military investments $\left(y_{k}\right)_{k \in N}$ to attack/defend (or both) their region. After this investment, countries sequentially engage in bilateral warfare or bargaining. The order of sequential moves is determined by the river structure $\pi$ with the first war /bargaining taking place between the two most downstream countries $n$ and $n-1$. Each time, a downstream country $k+1$ makes war or bargains with its upstream country $k$ over the available water $X_{k}$ at country $k$. If country $k+1$ makes war with its upstream neighbouring country $k$, then it wins the war with probability $p_{k+1}=p\left(y_{k+1}, y_{k}\right)$, and loses with probability $\left(1-p_{k+1}\right)=\left(1-p\left(y_{k+1}, y_{k}\right)\right)$.

\footnotetext{
${ }^{2}$ These are weaker assumptions than Ambec and Sprumont (2002) who assume the benefit functions to be strictly increasing and strictly concave. Ambec and Ehlers (2008) and van den Brink, van der Laan and Moes (2012) also require strict concavity, but do not require the benefit function to be increasing.
} 
The function $p$, expressing that the probability of winning depends on the military investments, is known as a contest success function. We assume that, for every pair of neighbouring countries $k$ and $k+1$, the contest success function $p\left(y_{k+1}, y_{k}\right)$ satisfies the following usual conditions ${ }^{3}$ :

(a) $p(\cdot)$ is twice differentiable.

(b) $p\left(y_{k+1}, y_{k}\right)+p\left(y_{k}, y_{k+1}\right)=1$.

(c) $\frac{\partial p\left(y_{k+1}, y_{k}\right)}{\partial y_{k+1}}>0$ and $\frac{\partial p\left(y_{k+1}, y_{k}\right)}{\partial y_{k}}<0$.

(d) $\frac{\partial^{2} p\left(y_{k+1}, y_{k}\right)}{\partial y_{k+1}^{2}}<0$.

Assume that country $k+1$ comes to a bargaining agreement with its downstream neighbour, and keeps a fraction $\delta_{k+1} \in[0,1]$ of its available water for itself. If country $k+1$ wins the war with its upstream neighbour $k$, then country $k+1$ has available an amount of $X_{k}+e_{k+1}$, being the full amount of water $X_{k}$ it obtained from the war with $k$, plus its own additional inflow $e_{k+1}$. According to the bargaining agreement with its downstream neighbour, it keeps an amount $\delta_{k+1}\left(X_{k}+e_{k+1}\right)$ for itself. If country $k+1$ loses the war with its upstream neighbour $k$, then it has only its own inflow $e_{k+1}$ available from which, again according to the bargaining agreement with its downstream neighbour, it keeps $\delta_{k+1} e_{k+1}$ for itself.

Concerning country $k$, if it wins the military conflict with its downstream neighbour $k+1$ (which occurs with probability $\left.\left(1-p_{k+1}\right)=\left(1-p\left(y_{k+1}, y_{k}\right)\right)\right)$ then country $k$ keeps the available amount $X_{k}$ for itself, and if it loses (which occurs with probability $p_{k+1}=p\left(y_{k+1}, y_{k}\right)$ ) then it loses all available water.

Thus, the expected payoff $u_{k}^{w}$ to upstream country $k$, and $u_{k+1}^{w}$ to downstream country $k+1$ from bilateral warfare, assuming that country $k+1$ comes to a bilateral bargaining agreement $\left(\delta_{k+1}\right)$ with its downstream neighbour $k+2(\leqslant n)$, is

$$
u_{k}^{w}=u_{k}^{w}\left(y_{k}, y_{k+1}\right)=\left(1-p_{k+1}\right) B_{k}\left(X_{k}\right)+p_{k+1} B_{k}(0),
$$

and

$$
u_{k+1}^{w}=u_{k+1}^{w}\left(y_{k}, y_{k+1}\right)=p_{k+1} B_{k+1}\left(\delta_{k+1}\left(X_{k}+e_{k+1}\right)\right)+\left(1-p_{k+1}\right) B_{k+1}\left(\delta_{k+1} e_{k+1}\right),
$$

\footnotetext{
${ }^{3}$ These are standard assumptions for contest success functions that were first axiomatized by Skaperdas(1996).
} 
where the utility depends on the military investments through the contest success function $p_{k+1}=$ $p\left(y_{k+1}, y_{k}\right)$. The first term in the payoff $u_{k}^{w}$ is the benefit for upsteam country $k$ from consuming the amount $X_{k}$ that it keeps if it wins the war with country $k+1$, which happens with probability $\left(1-p_{k+1}\right)$. The second term is the benefit for country $k$ from consuming a zero amount of water, which occurs if it loses the war with country $k+1$, and thus happens with probability $p_{k+1}$.

The first term in the payoff $u_{k+1}^{w}$, is the benefit for the downstream country $k+1$ from consuming the amount $\delta_{k+1}\left(X_{k}+e_{k+1}\right)$ which is the sum of the water $X_{k}$ which it obtains from its upstream neighbour after winning the war with this neighbour (which happens with probability $p_{k+1}$ ), and its own inflow $e_{k+1}$, taking into account the bargaining outcome $\delta_{k+1}$ of the bargaining with its downstream neighbour $k+2$. The second term is the benefit for country $k+1$ from consuming only its own inflow, which is its water consumption if it loses the war with its upstream neighbour $k$, which happens with probability $\left(1-p_{k+1}\right.$ ) (again taking into account the bargaining outcome $\delta_{k+1}$ of the bargaining with its downstream neighbour $k+2$ ).

On the other hand, if the two countries bargain and mutually agree that country $k$ will keep a fraction $\delta_{k}$ of $X_{k}$ for itself, the payoff $u_{k}^{b}$ to country $k$, and $u_{k+1}^{b}$ to country $k+1$ from bargaining is (again assuming that country $k+1$ comes to a bilateral bargaining agreement with its downstream neighbour $k+2 \leqslant n$ ), given by

$$
\begin{aligned}
& \quad u_{k}^{b}=u_{k}^{b}\left(y_{k}\right)=B_{k}\left(\delta_{k} X_{k}\right), \\
& \text { and } \\
& u_{k+1}^{b}=u_{k+1}^{b}\left(y_{k+1}\right)=B_{k+1}\left(\delta_{k+1}\left(\left(1-\delta_{k}\right) X_{k}+e_{k+1}\right)\right)
\end{aligned}
$$

Here, the bargaining agreement is that country $k$ sends $\left(1-\delta_{k}\right) X_{k}$ of its water to country $k+1$, keeping $\delta_{k} X_{k}$ of the water for itself. Country $k+1$ then has available the amount $\left(1-\delta_{k}\right) X_{k}+e_{k+1}$ of which it keeps a fraction $\delta_{k+1}$ for itself and sends the rest downstream (where $\delta_{n}=1$ for the most downstream agent).

Notice that we wrote the payoffs in terms of bilateral bargaining between countries $k$ and $k+1$, but when pairs of countries sequentially bargain, starting with the two most downstream countries, then these payoffs are determined recursively. 


\section{Peaceful agreements: equilibrium and main result}

For a given military investment $\left(y_{k}, y_{k+1}\right), k=1, \ldots, n-1$, a no conflict (NC) condition determines when a credible bargaining agreement $\delta_{k}$ exists between two neighbouring countries. It means that for both countries, the payoffs from bargaining should be at least equal to the payoffs from warfare.

$$
\mathrm{NC}: \quad u_{k}^{b} \geqslant u_{k}^{w} \text { and } u_{k+1}^{b} \geqslant u_{k+1}^{w}
$$

We speak about a peaceful agreement if on the river each pair of neighbouring countries prefer bargaining over warfare, i.e. the no conflict conditions $\mathrm{NC}$ are satisfied.

Definition 3.1. A peaceful agreement is a tuple $\left(\delta_{k}\right)_{k \in\{1, \ldots, n-1\}}$ such that the $N C$ conditions are satisfied for every $k \in\{1, \ldots, n-1\}$.

Let $\left[\underline{\delta}_{k}, 1\right]$ be the set of possible values of $\delta_{k}$ that satisfy the inequality $u_{k}^{b} \geqslant u_{k}^{w}$, where $\underline{\delta}_{k}$ satisfies $u_{k}^{b}=u_{k}^{w}{ }^{4}$ This is the set of possible values for which country $k$ prefers bargaining over warfare with its downstream neighbour $k+1$. Similarly, let $\left[0, \bar{\delta}_{k}\right]$ be the set of possible values for $\delta_{k}$ that satisfy $u_{k+1}^{b} \geqslant u_{k+1}^{w}$, being the values where country $k+1$ prefers bargaining over warfare with its upstream neighbour $k{ }^{5}$ In order that the NC condition is satisfied, there must exist a $\delta_{k} \in\left[\underline{\delta}_{k}, \bar{\delta}_{k}\right]$, i.e. $\underline{\delta}_{k} \leqslant \bar{\delta}_{k}$.

Notice that the possible peaceful agreements, if they exist, depend on the military investments through the contest success functions. However, it turns out that, if the benefit functions are nonnegative, increasing and concave, then irrespective of the military investments, a peaceful agreement always exists.

Proposition 3.1. If, for every $k=\{1,2 \ldots, n\}$, the benefit function $B_{k}($.$) is nonnegative, increasing$ and concave, then for every vector of military investments $y=\left(y_{1}, \ldots, y_{n}\right)$, there exists a peaceful agreement, i.e. $\underline{\delta}_{k} \leqslant \bar{\delta}_{k}$ for every $k=1, \ldots, n-1$.

\footnotetext{
${ }^{4}$ This set being an interval of this form follows from (1), (2) and the benefit functions being increasing in the amount of available water. This implies that, if $\delta_{k}$ satisfies the NC condition for country $k$, then every higher value satisfies this $\mathrm{NC}$ condition.

${ }^{5}$ This set being an interval of this form follows similar as in Footnote 4 for country $k$.
} 
The proof of this proposition can be found in Appendix A. Proposition 3.1 guarantees the existence of a peaceful agreement, i.e. a family of bargaining shares $\left(\delta_{k}\right)_{k \in\{1, \ldots, n-1\}}$ such that $\underline{\delta}_{k} \leqslant$ $\delta_{k} \leqslant \bar{\delta}_{k}$ for all $k=1,2 \ldots, n-1$. This is an important result for water negotiations since it implies that, although the military capacities of countries might be a threat and make it more difficult to get to an agreement, it is always possible to have a peaceful agreement and avoid warfare.

Remark 1. When the benefit functions are strictly concave, then for every two values of $\delta_{k}$ satisfying the NC conditions, also every convex combination satisfies these conditions, and thus there exists a continuum of values, $\delta_{k} \in\left[\underline{\delta}_{k}, \bar{\delta}_{k}\right]$ that countries could bilaterally agree on.

\section{A scenario for specific bargaining outcomes}

In the previous section, we showed that a peaceful agreement is always possible. In this section, we present a mechanism that shows how one specific such an agreement can be implemented. To maximise its own benefit, country $k$ wants to agree on $\bar{\delta}_{k}$ (having $\delta_{k}$ as high as possible), while country $k+1$ will want to agree on getting the offer $\left(1-\underline{\delta}_{k}\right)$ (having $\delta_{k}$ as low as possible). What value of $\delta_{k}$ to apply might depend on the bargaining strength of the countries, but also on water allocation principles from International Water Law. Applying the principle of Absolute Territorial Sovereignty (ATS), the upstream country has control over the water that flows on its territory, and we therefore assume that country $k$ holds the upper hand. Then, it proposes $\delta_{k}=\bar{\delta}_{k}$, where its downstream neighbour is pushed to its payoff under warfare, $u_{k+1}^{b}=u_{k+1}^{w}$, meaning that

$$
B_{k+1}\left(\delta_{k+1}\left(\left(1-\bar{\delta}_{k}\right) X_{k}+e_{k+1}\right)\right)=p_{k+1} B_{k+1}\left(\delta_{k+1}\left(X_{k}+e_{k+1}\right)\right)+\left(1-p_{k+1}\right) B_{k+1}\left(\delta_{k+1} e_{k+1}\right)
$$

Assuming this to be the case for every pair of neighbouring countries, through backward induction we can replace the $\delta_{k+1}$ 's in this equation by the agreeable values $\left(\bar{\delta}_{k+1}\right)_{k \in\{1, \ldots, n-1\}}$ with $\bar{\delta}_{n}=1$, giving payoffs

$$
u_{k+1}^{b}=B_{k+1}\left(\bar{\delta}_{k+1}\left(\left(1-\bar{\delta}_{k}\right) X_{k}+e_{k+1}\right)\right), k=1, \ldots, n-1
$$


The agreement $\bar{\delta}_{k}$ depends on a number of factors: the amount of water $X_{k}$ that is available to country $k$, the flow $e_{k+1}$ entering the river at the territory of country $k+1$, the military investments $y_{k}$ and $y_{k+1}$ (through the contest success function $p_{k+1}$ ), and the slope of the benefit function.

Next, we introduce a mechanism that induces the $\bar{\delta}_{k}$ 's as Subgame Perfect Equilibrium (SPE) outcomes. In this mechanism, we translate the ATS principle by letting, at every segment of the river, the upstream country be the proposer in the bargaining with its downstream neighbour.

Consider the following extensive form game where pairs of neighbouring countries sequentially perform bilateral bargaining, starting from the most downstream pair, with the possibility to engage in warfare in case there is no agreement. At each stage/segment $k$, country $k$ bargains with its downstream neighbouring country $k+1$ over an amount $X_{k} \geqslant 0$. Based on the ATS principle, we assume the upstream country is the proposer who can make a take-it or leave-it offer $\delta_{k}$. The downstream country is the responder who either accepts $(A)$ or rejects $(R)$ the offer. Accepting the offer implies that country $k+1$ receives $\left(1-\delta_{k}\right) X_{k}$, and country $k$ keeps $\delta_{k} X_{k}$ for itself. Rejecting implies that countries $k$ and $k+1$ enter a war.

We assume that country $k$ 's strategy is Markovian: it depends on the current state of the world and is independent of history. If country $k$ is a proposer, its strategy ${ }^{6}$ is a function of the available water and is denoted by $\rho_{k}^{p}\left(X_{k}\right)=\delta_{k} \in[0,1]$. Since country $k+1$ is the responder in its negotiation with country $k$, its strategy is a function of the offer made by the proposer $k$, and is denoted by $\rho_{k+1}^{r}\left(\delta_{k}\right) \in\{A, R\}$. Observe that, as country 1 is never a responder, we have $\rho_{1}^{r}\left(\delta_{0}\right)=\rho_{1}^{r}(0)=A$. Since country $n$ is never a proposer, we have $\rho_{1}^{p}\left(X_{n}\right)=1$. We make the following assumptions on the strategy function.
(A1) $\rho_{k}^{p}(0)=0$.
(A2) $\rho_{k}^{r}(0)=A$.

\footnotetext{
${ }^{6}$ Throughout the paper, we will be somewhat sloppy, and refer to the actions of a player as proposer or responder as a strategy in a bilateral bargaining. Formally, a strategy specifies an action in every decision point where the player might have to choose an action. So, a strategy for $k=1, \ldots n$, is a pair of functions $\left(\rho_{k}^{p}, \rho_{k}^{r}\right)$, where $\rho_{k}^{p}$ is country $k$ 's action as a proposer to its downstream neighbour, and $\rho_{k}^{r}$ is country $k$ 's action as a responder to its upstream neighbour.
} 
(A1) implies that if a country has zero water supply or has no control over its own water supply, i.e. $X_{k}=0$, then it offers everything (being zero) to its downstream neighbour $k+1$. (A2) implies that if an upstream country $k$ offers all its water supply, i.e. $\delta_{k}=0$, then the downstream country $k+1$ always accepts the offer (also if there is no water to bargain for).

In every subgame of this extensive form game, there is bargaining between each pair of neighbouring countries $k \in\{1, \ldots, n-1\}$ and $k+1$, with bargaining share $\bar{\delta}_{k}$ being the most beneficial for the upstream country $k$, and $\underline{\delta}_{k}$ being the most beneficial for the downstream country $k+1$. It turns out that this game has a unique Subgame Perfect Equilibrium, and in this equilibrium the proposing countries propose their best option, which is accepted by their downstream neighbour.

Proposition 4.1. Suppose that, for every $k \in\{1,2 \ldots, n\}$, the benefit function $B_{k}($.$) is nonnegative,$ increasing and concave. Then, there exists a unique Subgame Perfect Equilibrium (SPE) $\rho=$ $\left(\left\{\rho_{1}^{p}, \rho_{1}^{r}\right\},\left\{\rho_{2}^{p}, \rho_{2}^{r}\right\}, \ldots,\left\{\rho_{n}^{p}, \rho_{n}^{r}\right\}\right)$. In this SPE, countries $k=1, \ldots n-1$ propose $\rho_{k}^{p}\left(X_{k}\right)=\bar{\delta}_{k}$ to their downstream neighbour $k+1$, who accepts this offer, so $\rho_{k}^{r}\left(\bar{\delta}_{k}\right)=$ A for all $k=1, \ldots, n$.

The proof of this proposition also can be found in Appendix A.

\section{Concluding remarks and future research}

In this paper, we considered a situation where countries located along a transboundary river choose between a peaceful bargaining over the available river water or engaging in warfare. We showed that the benefit functions of all countries along the transboundary river being nonnegative, increasing and concave, are sufficient conditions for the existence of a peaceful agreement, see Proposition 3.1. This is a very useful result for real life river water negotiations, since it implies that negotiating parties should be able to avoid warfare and manage to get a bargaining agreement if these conditions are satisfied, even without an external authority. After this main result, we also provided a scenario/mechanism that implements one specific set of bargaining proposals, namely those that are most beneficial for the upstream countries.

On the other hand, necessary conditions can be useful if there is an authority which could manipulate the incentives of the countries in such a way that these conditions are satisfied. But without 
such an authority, sufficient conditions are more useful. However, finding necessary conditions is a plan for future research. As a first step in finding necessary conditions, we can conclude that, if all benefit functions are nonnegative, increasing and strictly convex, then there can never be a peaceful agreement. ${ }^{7}$ From this, we can conclude that strictly convex benefit functions always lead to warfare if there is no intervention, and one needs an authority which can influence the incentives or benefit functions to avoid warfare. Although it is unlikely that the benefit functions are strictly convex, it is useful to know that an external authority might be needed to create the possibility of bargaining agreements between neighbouring countries in situations when the benefit functions have some convexity involved.

We saw that concavity guarantees the existence of a peaceful agreement, and strict convexity implies nonexistence. However, if the benefit functions are concave at some but strictly convex at other amounts of water consumption, then a bargaining agreement may, but need not, exist. We hope that for rivers with concave benefit functions, our result motivates the countries to come to a peaceful bargaining agreement, and avoid warfare.

Besides showing existence of the possibility for a peaceful agreement, we presented a specific mechanism that implements a peaceful agreement. Specifically, using the ATS principle, we gave the upper hand to the upstream country in negotiations with its downstream neighbour, and provided a mechanism which unique SPE results in a peaceful agreement where the bargaining proposal is the most advantageous one for the upstream country. Using other water allocation principles, such as the principles of Unlimited Territorial Integrity (UTI) ${ }^{8}$ or Territorial Integrity of all Basin States $(\mathrm{TIBS})^{9}$, might give the downstream country the upper hand, or have a more balanced bargaining

\footnotetext{
${ }^{7}$ If $B($.$) is nonnegative, increasing, and strictly convex, then by a similar reasoning as in the proof of Proposition$ 3.1 in Appendix A, it can be shown that for every vector of military investments $y=\left(y_{1}, \ldots, y_{n}\right), \underline{\delta}_{k}>\left(1-p_{k+1}\right)$ and $\bar{\delta}_{k}<\left(1-p_{k+1}\right)$. Therefore, $\underline{\delta}_{k}>\left(1-p_{k+1}\right)>\bar{\delta}_{k}$, and hence, there exists no peaceful agreement.

${ }^{8}$ The UTI principle says that upstream countries should not change the natural flow of the water at the expense of its downstream countries'. This is clearly in favor of downstream countries.

${ }^{9}$ TIBS says that the water of an international watercourse belongs to all basin states combined, no matter where it enters the watercourse. It does not make any country the legal owner of water. Each basin state is entitled to a reasonable and equitable share in the optimal use of the available water. This gives a more balanced position to the two countries in a bilateral bargaining over water.
} 
advantage. These water allocation principles are discussed in, e.g. Lipper (1967) and Kilgour and Dinar (1995).

We finally remark that the military investments in this paper were only used to set the winning probabilities $p_{k+1}=p\left(y_{k+1}, y_{k}\right)$ of the possible war between countries $k$ and $k+1$, in case they do not reach an agreement. Notice that in the use of these winning probabilities, the military investments are not playing a role, and we could have phrased everything in terms of exogenous winning probabilities. We presented these probabilities as being determined by military investments, since these investments are a main factor in determining the strength of countries in military warfare.

\section{Appendix A: Proofs}

\section{Proof of Proposition 3.1}

Proof. We have to show that there exists a $\delta_{k} \in(0,1)$ satisfying the No-Conflict (NC) conditions for any pair of neighbouring countries $k \in\{1, \ldots, n-1\}$ and $k+1$.

The NC condition for country $k$ is

$$
B_{k}\left(\delta_{k} X_{k}\right) \geqslant\left(1-p_{k+1}\right) B_{k}\left(X_{k}\right)+p_{k+1} B_{k}(0)
$$

As the function $B_{k}($.$) is concave,$

$$
B_{k}\left(\left(1-p_{k+1}\right) \cdot X_{k}+p_{k+1} \cdot 0\right) \geqslant\left(1-p_{k+1}\right) B_{k}\left(X_{k}\right)+p_{k+1} B_{k}(0)
$$

which is equivalent to

$$
B_{k}\left(\left(1-p_{k+1}\right) \cdot X_{k}\right) \geqslant\left(1-p_{k+1}\right) B_{k}\left(X_{k}\right)+p_{k+1} B_{k}(0)
$$

Let $\underline{\delta}_{k}$ be such that the bound for (3) is reached:

$$
B_{k}\left(\underline{\delta}_{k} \cdot X_{k}\right)=\left(1-p_{k+1}\right) B_{k}\left(X_{k}\right)+p_{k+1} B_{k}(0),
$$

and thus with (4),

$$
B_{k}\left(\left(1-p_{k+1}\right) \cdot X_{k}\right) \geqslant B_{k}\left(\underline{\delta}_{k} \cdot X_{k}\right)
$$


As $B_{k}($.$) is increasing, this implies$

$$
\left(1-p_{k+1}\right) \geqslant \underline{\delta}_{k}
$$

Similarly, the NC condition for country $k+1$ is

$$
B_{k+1}\left(\delta_{k+1}\left(\left(1-\delta_{k}\right) X_{k}+e_{k+1}\right)\right) \geqslant p_{k+1} B_{k+1}\left(\delta_{k+1}\left(X_{k}+e_{k+1}\right)\right)+\left(1-p_{k+1}\right) B_{k+1}\left(\delta_{k+1} e_{k+1}\right)
$$

Again, as the function $B_{k+1}($.$) is concave,$

$$
\begin{aligned}
B_{k+1}\left(p_{k+1} \delta_{k+1}\left(X_{k}+e_{k+1}\right)+\left(1-p_{k+1}\right) \delta_{k+1} e_{k+1}\right) \geqslant & p_{k+1} B_{k+1}\left(\delta_{k+1}\left(X_{k}+e_{k+1}\right)\right) \\
& \left.+\left(1-p_{k+1}\right) B_{k+1}\left(\delta_{k+1} e_{k+1}\right)\right)
\end{aligned}
$$

Let $\bar{\delta}_{k}$ be such that the bound in (6) is reached:

$$
B_{k+1}\left(\delta_{k+1}\left(\left(1-\bar{\delta}_{k}\right) X_{k}+e_{k+1}\right)\right)=p_{k+1} B_{k+1}\left(\delta_{k+1}\left(X_{k}+e_{k+1}\right)\right)+\left(1-p_{k+1}\right) B_{k+1}\left(\delta_{k+1}\left(e_{k+1}\right)\right)
$$

(Notice that $\bar{\delta}_{k}$ might depend on $\delta_{k+1}$. However, it is always greater or equal to $\underline{\delta}_{k}$, which does not depend on further negotiations downstream.) Since the right-hand sides of (7) and (8) are the same, these (in)equalities give

$$
\begin{gathered}
B_{k+1}\left(p_{k+1} \delta_{k+1}\left(X_{k}+e_{k+1}\right)+\left(1-p_{k+1}\right) \delta_{k+1} e_{k+1}\right) \\
\left.\geqslant p_{k+1} B_{k+1}\left(\delta_{k+1}\left(X_{k}+e_{k+1}\right)\right)+\left(1-p_{k+1}\right) B_{k+1}\left(\delta_{k+1} e_{k+1}\right)\right) \\
=B_{k+1}\left(\delta_{k+1}\left(\left(1-\bar{\delta}_{k}\right) X_{k}+e_{k+1}\right)\right) .
\end{gathered}
$$

As $B_{k+1}($.$) is increasing, this implies$

$$
p_{k+1} \delta_{k+1}\left(X_{k}+e_{k+1}\right)+\left(1-p_{k+1}\right) \delta_{k+1} e_{k+1} \geqslant \delta_{k+1}\left(\left(1-\bar{\delta}_{k}\right) X_{k}+e_{k+1}\right)
$$

which is equivalent to

$$
p_{k+1} \delta_{k+1} X_{k}+p_{k+1} \delta_{k+1} e_{k+1}+\delta_{k+1} e_{k+1}-p_{k+1} \delta_{k+1} e_{k+1} \geqslant \delta_{k+1} X_{k}-\delta_{k+1} \bar{\delta}_{k} X_{k}+\delta_{k+1} e_{k+1}
$$


which is equivalent to

$$
\delta_{k+1} \bar{\delta}_{k} X_{k} \geqslant\left(1-p_{k+1}\right) \delta_{k+1} X_{k}
$$

Since this must hold for any $X_{k} \geqslant 0$ and $\delta_{k+1} \in[0,1]$, we have

$$
\bar{\delta}_{k} \geqslant 1-p_{k+1}
$$

Taking the two cases together, (5) and (9) give $\underline{\delta}_{k} \leqslant 1-p_{k+1} \leqslant \bar{\delta}_{k}$, implying that $\underline{\delta}_{k} \leqslant \bar{\delta}_{k}$.

\section{Proof of Proposition 4.1}

The mechanism described in Section 4, is formally given in Appendix B.

Proof. We (i) give a specific strategy profile and verify that it is a SPE, and (ii) show that this is the unique SPE.

(i) Consider the following strategy profile:

$$
\rho_{k}^{p}\left(X_{k}\right)=\bar{\delta}_{k} \text { for all } k=1, \ldots, n-1,
$$

and for every $k=2, \ldots n$,

$$
\rho_{k}^{r}\left(\delta_{k-1}\right)= \begin{cases}A & \text { if } \delta_{k-1} \leqslant \bar{\delta}_{k-1} \\ R & \text { if } \delta_{k-1}>\bar{\delta}_{k-1}\end{cases}
$$

We first show that this is a SPE. Obviously, the outcome according to this strategy profile leads to proposals $\bar{\delta}_{k}$ which are accepted by each downstream neighbour.

Starting from the most downstream pair of countries, rejection of any proposal $\delta_{n-1} \geqslant \bar{\delta}_{n-1}$ by country $n$, leads to warfare which gives country $n$ the same payoff as accepting the proposal. So, rejecting proposal $\delta_{n-1} \geqslant \bar{\delta}_{n-1}$ is a best response for country $n$. Accepting proposals $\delta_{n-1} \leqslant \bar{\delta}_{n-1}$ gives country $n$ at least as much payoff as warfare, so accepting is a best response.

For country $n-1$, proposing $\delta_{n-1}<\bar{\delta}_{n-1}$ also will be accepted, but results in a lower payoff for country $n-1$ by the benefit function being increasing. Proposing $\delta_{n-1}>\bar{\delta}_{n-1}$ will be rejected, which does not result in a higher payoff for country $n-1$, since

$$
\left(1-p_{n}\right) B\left(X_{n-1}\right)+p_{n} B(0) \leqslant B\left(\left(1-p_{n}\right) X_{n-1}+p_{n} \cdot 0\right)
$$




$$
\left.=B\left(\left(1-p_{n}\right) X_{n-1}\right)\right) \leqslant B\left(\bar{\delta}_{n-1} X_{n-1}\right),
$$

where the first inequality follows from concavity, and the second inequality follows from $B$ being increasing and $\bar{\delta}_{n-1} \geqslant 1-p_{n}$ (see (9) in the proof of Proposition 3.1). Thus, proposal $\bar{\delta}_{n-1}$ is a best response $^{10}$ of country $n-1$ to the acceptance strategy of country $n$.

Going to the next pair of neighbouring countries, in its negotiation with country $n-2$, country $n-1$ accepting the proposal $\bar{\delta}_{n-2}$ gives the same payoff as warfare, given that it comes to a bargaining agreement with country $n$. So, accepting proposal $\bar{\delta}_{n-2}$ is part of a best response for country $n-1$. Similar as above, proposing $\bar{\delta}_{n-2}$ is part of a best response for country $n-2$. Continuing this reasoning inductively upstream the river, in each stage it is a best response for country $k+1$ to accept all proposals smaller or equal to $\bar{\delta}_{k}$, and for country $k$ to propose $\bar{\delta}_{k}$. This shows that the given strategy profile is a SPE.

(ii) Next, we show that there is no other SPE in which either a proposal different from $\bar{\delta}_{k}, k=$ $1, \ldots, n-1$ is accepted, or a country $k=2, \ldots, n$ rejects the proposal $\bar{\delta}_{k-1}$.

Suppose that $\rho^{\prime}$ is another SPE.

It is easy to verify for country $n$, that in any SPE it should accept any proposal $\delta_{n-1}<\bar{\delta}_{n-1}$, and reject any proposal $\delta_{n-1}>\bar{\delta}_{n-1}$. If $\delta_{n-1}=\bar{\delta}_{n-1}$, then rejecting is also a best response. (Above we already saw that in that case, accepting is a best response.)

Suppose that $\rho^{\prime}$ is such that $\rho_{n}^{\prime r}\left(\bar{\delta}_{n-1}\right)=R$, so country $n$ rejects the proposal $\bar{\delta}_{n-1}$. Since every proposal $\delta_{n-1} \in\left(\underline{\delta}_{n-1}, \bar{\delta}_{n-1}\right)$ would be accepted by country $n$, and gives country $n-1$ a higher payoff than proposal $\bar{\delta}_{n-1}$ (which would be rejected and result in war), $\delta_{n-1} \geqslant \bar{\delta}_{n-1}$ cannot be part of a SPE where country $n$ rejects the proposal $\bar{\delta}_{n-1}$. But $\delta_{n-1}<\bar{\delta}_{n-1}$ cannot be part of a SPE since then $\widehat{\delta}_{n-1} \in\left(\delta_{n-1}, \bar{\delta}_{n-1}\right)$ would also be accepted and give a higher payoff for country $n-1$. Concluding, in SPE, country $n$ must accept the proposal $\bar{\delta}_{n-1}$. Then, country $n-1$ 's best response is to propose $\bar{\delta}_{n-1}$ since a proposal $\delta_{n-1}<\bar{\delta}_{n-1}$ will be accepted but give a lower payoff to country

\footnotetext{
${ }^{10}$ As mentioned before, we are somewhat sloppy in terminology, speaking about best responses even though this is not a full strategy of country $n-1$. A full strategy includes the acceptance strategy of country $n-1$ in its negotiations with country $n-2$.
} 
$n-1$ (because of the increasing benefit function), and a proposal $\delta_{n-1}>\bar{\delta}_{n-1}$ will be rejected and lead to a lower payoff. Thus, $\delta_{n-1} \neq \bar{\delta}_{n-1}$ cannot be part of an SPE.

So, in every SPE, country $n-1$ makes proposal $\bar{\delta}_{n-1}$ which is accepted by country $n$.

Continuing by Backward Induction, assuming that every pair $k, k+1, k=1, \ldots n-1$, will agree on $\bar{\delta}_{k}$, we see that the strategy profile given by (10) and (11) is the only SPE.

\section{Appendix B: Mechanism of Section 4}

First, the two most downstream countries $n-1$ and $n$ bargain, and then sequentially the countries bargain bilateral from downstream to upstream. Applying the ATS principle, let at each stage country $k=n-1, \ldots, 1$ make a proposal to its downstream neighbour $k+1$ (who thus already resolved its bargaining with country $k+2)^{11}$, which country $k+1$ can accept or reject. In case a pair of countries engages in warfare, this war is fought after all negotiations are finished. ${ }^{12}$

In case of acceptance in bilateral bargaining between country $k=1, \ldots n-1$ and country $k+1$, the payoffs, denoted by $u_{k}^{A}$ and $u_{k+1}^{A}$, are (where $u_{k}^{b}$ and $u_{k+1}^{b}$ are given by (2))

$$
u_{k}^{A}=u_{k}^{b}=B_{k}\left(\delta_{k} X_{k}\right)
$$

and $^{13}$

\footnotetext{
${ }^{11}$ Note that $k+2$ does not exist when $k=n-1$. In the following, we ignore bargaining with $k+2$ if $k=n-1$.

${ }^{12}$ Because the negotiations are finished before the wars are ended, the full amount of water available for country $k$, including what it obtained from its upstream neighbour (either by bargaining or by warfare), is at stake in a water war with its downstream neighbour $k+1$.

${ }^{13}$ Notice that, in the first stage of bargaining between countries $n-1$ and $n$, for country $n$ there is no bargaining with a downstream neighbour of $n$, and therefore the last case of disagreeing with its downstream neighbour cannot occur. The same for (14).
} 


$$
u_{k+1}^{A}=\left\{\begin{array}{r}
u_{k+1}^{b}=B_{k+1}\left(\delta_{k+1}\left(\left(1-\delta_{k}\right) X_{k}+e_{k+1}\right)\right) \\
\text { if } k+1 \text { agreed on } \delta_{k+1} \text { with its downstream neighbour } k+2 \\
\left.\left(1-p_{k+2}\right) B_{k+1}\left(\left(1-\delta_{k}\right) X_{k}+e_{k+1}\right)\right)+p_{k+2} B_{k+1}(0) \\
\text { if } k+1 \text { engaged in warfare with its downstream neighbour } k+2 .
\end{array}\right.
$$

In case of rejection in bilateral bargaining between country $k=1, \ldots n-1$ and country $k+1$, the payoffs, denoted by $u_{k}^{R}$ and $u_{k+1}^{R}$, (where $u_{k}^{w}$ and $u_{k+1}^{w}$ are given by (1)), are

$$
u_{k}^{R}=u_{k}^{w}=\left(1-p_{k+1}\right) B_{k}\left(X_{k}\right)+p_{k+1} B_{k}(0)
$$

and

$$
u_{k+1}^{R}=\left\{\begin{array}{r}
u_{k+1}^{w}=p_{k+1} B_{k+1}\left(\delta_{k+1}\left(X_{k}+e_{k+1}\right)\right)+\left(1-p_{k+1}\right) B_{k+1}\left(\delta_{k+1} e_{k+1}\right) \\
\text { if } k+1 \text { agreed on } \delta_{k+1} \text { with its downstream neighbour } k+2 \\
\left(1-p_{k+2}\right)\left(p_{k+1} B_{k+1}\left(\delta_{k+1}\left(X_{k}+e_{k+1}\right)\right)+\left(1-p_{k+1}\right) B_{k+1}\left(\delta_{k+1} e_{k+1}\right)\right)+p_{k+2} B_{k+1}(0) \\
\text { if } k+1 \text { engaged in warfare with its downstream neighbour } k+2
\end{array}\right.
$$

Formally, the mechanism looks as follows:

Stage 1: Set $s=1$. Goto Step 1 .

STEP 1 Country $n-1$ proposes $\delta_{n-1} \in[0,1]$ to country $n$ (meaning that it offers country $n$ a share $\left(1-\delta_{n-1}\right)$ of the available amount of water $X_{n-1}$, and keeps a share $\delta_{n-1}$ for itself). Goto Step 2.

STEP 2 Country $n$ accepts or rejects the proposal.

If it accepts the proposal, then country $n$ earns payoff given by the first expression in (13). 
If it rejects the proposal, then country $n$ earns payoff given by the first expression in (14). Goto Stage 2.

Stage $s+1, s \in\{1, \ldots, n-2\}$ : Set $s=s+1$ and $k=n-s$. Goto Step 1 .

STEP 1 Country $k$ proposes $\delta_{k} \in[0,1]$ to country $k+1$ (meaning that it offers its downstream neighbour $k+1$ a share $\left(1-\delta_{k}\right)$ of the available amount of water $X_{k}$, and keeps a share $\delta_{k}$ for itself.). Goto Step 2.

STEP 2 Country $k+1$ accepts or rejects the proposal.

(i) If $k+1$ accepts the proposal, and its proposal $\delta_{k+1}$ to country $k+2$ in Stage $n-k$ is accepted, then country $k+1$ earns payoff as given by the first expression in (13). Goto Step 3.

(ii) If $k+1$ accepts the proposal, and its proposal $\delta_{k+1}$ to country $k+2$ in Stage $n-k$ is rejected, then country $k+1$ earns payoff as given by the second expression in (13). Goto Step 3.

(iii) If $k+1$ rejects the proposal, and its proposal $\delta_{k+1}$ to country $k+2$ in Stage $n-k$ is accepted, then country $k+1$ earns payoff as given by the first expression in (14). Goto Step 3.

(iv) If $k+1$ rejects the proposal, and its proposal $\delta_{k+1}$ to country $k+2$ in Stage $n-k$ is rejected, then country $k+1$ earns payoff as given by the second expression in (14). Goto Step 3.

STEP 3 If $s=n-1$ (and thus $k=1$ ) then Stop.

Otherwise, Goto Stage $s+1$. 


\section{References}

[1] Alcalde-Unzu, J., Gómez-Rua, M. and Molis, E., 2015. "Sharing the costs of cleaning a river: the Upstream Responsibility rule". Games and Economic Behavior, 90, pp. 134-150.

[2] Ambec, S. and Ehlers, L., 2008. "Sharing a river among satiable agents". Games and Economic Behavior, 64(1), pp.35-50.

[3] Ambec, S. and Ehlers, L., 2016. "Regulation via the Polluter-pays Principle". The Economic Journal, 126(593), pp.884-906.

[4] Ambec, S. and Sprumont, Y., 2002. "Sharing a river". Journal of Economic Theory, 107(2), pp.453-462.

[5] Ambec, S., Dinar, A. and McKinney, D., 2013. "Water sharing agreements sustainable to reduced flows". Journal of Environmental Economics and Management, 66(3), pp.639-655.

[6] Ansink, E. and Weikard, H.P., 2012. "Sequential sharing rules for river sharing problems". Social Choice and Welfare, 38(2), pp.187-210.

[7] Ansink, E. and Weikard, H.P., 2009. 'Contested water rights'. European Journal of Political Economy, 25(2), pp.247-260

[8] Ansink, E. and Weikard, H.P., 2015. Composition properties in the river claims problem. Social Choice and Welfare, 44(4), pp.807-831.

[9] Barrett, S., 1994. 'Self-enforcing international environmental agreements', Oxford Economic Papers, vol. 46 (1), pp. 878-94.

[10] Bennett, Lynne L., Shannon E. Ragland, and Peter Yolles., 1998. "Facilitating international agreements through an interconnected game approach: The case of river basins". Conflict and cooperation on trans-boundary water resources, Springer, Boston, MA. pp. 61-85. 
[11] Béal, S., Ghintran, A., Rémila, E. and Solal, P., 2013. The river sharing problem: a survey, International Game Theory Review, vol. 15 (3), pp. 1-19.

[12] Blomquist, W., et al., "Decentralization of river basin management: a global analysis", The World Bank, 2005.

[13] Brink, R. van den, He, S. and Huang, J.P., 2018. "Polluted river problems and games with a permission structure", Games and Economic Behavior, vol. 108 (3), pp. 182-205.

[14] Brink, R. van den, van der Laan, G., and Moes, N., 2012. "Fair agreements for sharing international rivers with multiple springs and externalities", Journal of Environmental Economics and Management, vol. 63 (3), pp. 388-403.

[15] Carraro, C., Marchiori, C., and Sgobbi, A., 2005. "Applications of negotiation theory to water issues", The World Bank.

[16] Carraro, C., Marchiori, C., and Sgobbi, A., 2005. "Advances in negotiation theory: bargaining, coalitions, and fairness", The World Bank.

[17] Dinar, A., Ratner, A., and Yaron, D., 1992. "Evaluating cooperative game theory in water resources", Theory and decision, 32 (1), pp. 1-20.

[18] Dong, B., Ni, D., and Wang, Y., 2012. "Sharing a polluted river network", Environmental and Resource Economics, 53 (3), pp. 367-387.

[19] Kilgour, D. M., and Dinar, A., 1995. "Are stable agreements for sharing international river waters now possible?", No. 1474, The World Bank.

[20] Kilgour, D. M., and Dinar, A., 2001. "Flexible water sharing within an international river basin", Environmental and Resource Economics, 18(1), pp. 43-60.

[21] Lipper, J., 1967. "Equitable utilization", The law of international drainage basins, 15, pp. 29. 
[22] Ni, D., and Wang, Y., 2007. "Sharing a polluted river". Games and Economic Behavior, 60(1), pp.176-186.

[23] Skaperdas, S., 1996. "Contest success functions," Economic Theory,7, pp. 283-290.

[24] Supalla, Raymond, et al., 2002. "A game theory approach to deciding who will supply instream flow water 1", JAWRA Journal of the American Water Resources Association, 38 (4), pp. 959966. 